\title{
Biogenic volatile organic compound emissions during BEARPEX 2009 measured by eddy covariance and flux-gradient similarity methods
}

\author{
J.-H. Park ${ }^{1, *}$, S. Fares ${ }^{1,2}$, R. Weber ${ }^{1}$, and A. H. Goldstein ${ }^{1,3}$ \\ ${ }^{1}$ Department of Environmental Science, Policy, and Management, Division of Ecosystem Sciences, University of California, \\ Berkeley, USA \\ ${ }^{2}$ Consiglio per la ricerca e la sperimentazione in agricoltura - Research Center for the Soil-Plant System, Rome, Italy \\ ${ }^{3}$ Department of Civil and Environmental Engineering, University of California, Berkeley, USA \\ * current address: National Center for Atmospheric Research, Atmospheric Chemistry Division, Boulder, CO, USA
}

Correspondence to: A. H. Goldstein (ahg@berkeley.edu)

Received: 10 August 2012 - Published in Atmos. Chem. Phys. Discuss.: 24 September 2012

Revised: 2 December 2013 - Accepted: 3 December 2013 - Published: 9 January 2014

\begin{abstract}
The Biosphere Effects on AeRosols and Photochemistry EXperiment (BEARPEX) took place in Blodgett Forest, a Ponderosa pine forest in the Sierra Nevada of California, USA, during summer 2009. We deployed a proton transfer reaction-quadrupole mass spectrometer (PTRQMS) to measure fluxes and concentrations of biogenic volatile organic compounds (BVOCs). Eighteen ion species, including the major BVOC expected at the site, were measured sequentially at 5 heights to observe their vertical gradient from the forest floor to above the canopy. Fluxes of the 3 dominant BVOCs methanol, 2-Methyl-3-butene-2-ol (MBO), and monoterpenes were measured above the canopy by the disjunct eddy covariance (EC) method. Canopy-scale fluxes were also determined by the flux-gradient similarity method ( $K$-theory). A universal $K$ ( $\left.K_{\text {univ }}\right)$ was determined as the mean of individual $K$ 's calculated from the measured fluxes divided by vertical gradients for methanol, MBO, and monoterpenes. This $K_{\text {univ }}$ was then multiplied by the gradients of each observed ion species to compute their fluxes. The flux-gradient similarity method showed very good agreement with the disjunct EC method. Fluxes are presented for all measured species and compared to historical measurements from the same site, and used to test emission algorithms used to model fluxes at the regional scale. MBO was the dominant emission observed, followed by methanol, monoterpenes, acetone, and acetaldehyde. The flux-gradient similarity method is shown to be tenable, and we recommend
\end{abstract}

its use, especially in experimental conditions when fast measurement of BVOC species is not available.

\section{Introduction}

Defining source strengths of biogenic volatile organic compounds (BVOC; e.g., isoprene and monoterpenes) and understanding their role in ozone $\left(\mathrm{O}_{3}\right)$ and secondary organic aerosol (SOA) formation are critical issues in atmospheric chemistry and climate science (Chameides et al., 1988; Andreae and Crutzen, 1997; Fuentes et al., 2000; Jang et al., 2002). On the global scale, VOC emissions from terrestrial vegetation are estimated to be an order of magnitude greater than those from fossil fuel combustion (Guenther et al., 1995). Additional unmeasured organics in the atmosphere are assumed to exist in both the gas and particle phases (Goldstein and Galbally, 2007). Substantial evidence has also been presented for the emissions of highly reactive BVOCs from forest ecosystems that have yet to be adequately quantified and included in BVOC emission models (Kurpius and Goldstein, 2003; Di Carlo et al., 2004; Holzinger et al., 2005). More comprehensive observations are needed to better constrain the full range of BVOC emissions from ecosystems and their importance for atmospheric chemistry. 
Canopy-scale (horizontal scales of order $10^{2}-10^{3} \mathrm{~m}$ ) BVOC flux measurement techniques (e.g., eddy covariance, relaxed eddy accumulation, and surface layer gradient) have been increasingly implemented in recent years (Goldstein et al., 1996; Schade and Goldstein, 2001; Karl et al., 2002; Lee et al., 2005). The eddy covariance (EC) method using proton transfer reaction-quadrupole mass spectrometry (PTRQMS) is currently the most direct and reliable measurement for measuring BVOC fluxes at the canopy scale (Rinne et al., 2001; Karl et al., 2002; Lee et al., 2005). However, this instrument requires the user to decide beforehand which compounds to monitor for EC flux measurements and is generally used for a relatively small number in order to obtain adequate signal. Recently, use of the new PTR time of flight mass spectrometer (PTR-TOF-MS) allows measurement of full mass spectra at high mass resolution fast enough to measure fluxes for all masses simultaneously (Ruuskanen et al., 2011; Park et al., 2013), but it is more expensive than the PTR-QMS. The flux-gradient similarity approach, generally called $K$ theory, can be used for measuring fluxes at the canopy scale. In this method, the flux is calculated by multiplying the atmospheric eddy diffusivity $(K)$ by the vertical concentration gradient of trace gases (Baldocchi et al., 1988; Goldstein et al., 1996). In past applications for estimating BVOC fluxes using this approach, $K$ was determined from (i) turbulent exchange coefficients derived using Monin-Obukhov similarity theory but this method is indirect and highly uncertain for heterogeneous forest canopies (Fuentes et al., 1996), or (ii) direct flux and vertical gradient measurements of $\mathrm{H}_{2} \mathrm{O}$, $\mathrm{CO}_{2}$ or sensible heat; thus, this approach requires at least one more fast-response sensor to determine $K$. Then, $K$ was multiplied by a $30 \mathrm{~min}$ average vertical BVOC gradient measured by in situ gas chromatography (GC) (Goldstein et al., 1998; Schade et al., 2000). In this study, taking advantage of PTRQMS, determination of BVOC fluxes by this approach for a wide range of species should be possible using EC flux and vertical gradient measurements of a few dominant BVOCs to determine $K$, and then multiplying $K$ by vertical gradients for each of the observed BVOCs.

The Biosphere Effects on Aerosols and Photochemistry Experiment (BEARPEX) 2009 was designed to study the emissions of BVOC and their role in SOA formation, oxidant, and ozone photochemistry. As part of BEARPEX 2009, we deployed a PTR-QMS (Ionicon Analytik, Innsbruck, Austria) to measure EC fluxes and vertical gradients of BVOCs in a ponderosa pine plantation in the Sierra Nevada of California, USA, with the goals to (1) determine fluxes of BVOCs (17 species) by a combination of direct EC flux measurements and the flux-gradient similarity approach, (2) compare measured fluxes with historical measurements from the same site in order to highlight vegetation change effects on emissions, and (3) test emission algorithm for the main BVOC species emitted by the vegetation and provide basal emission factors that could be used to model fluxes at regional scale.

\section{Experiment}

\subsection{Measurement site}

The BEARPEX 2009 intensive field campaign took place in Blodgett Forest from 15 June to 31 July 2009. This site is a Ponderosa pine forest located in the western foothills of the Sierra Nevada of California, USA $\left(38.90^{\circ} \mathrm{N}, 120.63^{\circ} \mathrm{W}\right.$, $1315 \mathrm{~m}$ elevation), $\sim 75 \mathrm{~km}$ downwind of Sacramento, and has been described in detail elsewhere (Goldstein et al., 2000; Lamanna and Goldstein, 1999; Schade and Goldstein, 2001; Dillon et al., 2002). Briefly, the land is owned and operated by Sierra Pacific Industries (SPI), and the plantation is dominated by ponderosa pine (Pinus ponderosa $\mathrm{L}$.) trees with an average tree height of $8.7 \mathrm{~m}$ in 2009 . The understory is dominated by manzanita (Arctostaphylos spp.) and whitethorn (Ceanothus cordulatus). In summertime, winds at this site are predominantly westerly to southwesterly $\left(220-280^{\circ}\right)$ during the day and northeasterly at night $\left(30-60^{\circ}\right)$. This daytime wind pattern transports polluted air from the Sacramento urban area to the pine forest site, along with isoprene and its oxidation products dominantly emitted from oak forests $\sim 30 \mathrm{~km}$ southwest of the site (Dreyfus et al., 2002). The site is characterized by a Mediterranean type climate, with the majority of precipitation occurring between September and May, and almost no rain in the summer. Average daily temperature ranged from $12^{\circ}$ to $26^{\circ} \mathrm{C}$ during the campaign period, with no rain recorded.

Two towers were set up at this site. One was a $15 \mathrm{~m}$ tall walk-up tower that had been installed in 1997. Meteorological parameters such as air temperature, humidity, wind speed and direction, and photosynthetically active radiation (PAR) were measured continuously from this tower (at $12.5 \mathrm{~m}, 8.75 \mathrm{~m}, 4.9 \mathrm{~m}, 3.0 \mathrm{~m}$, and $1.2 \mathrm{~m}$ ) and stored in $30 \mathrm{~min}$ averaged data sets. Ecosystem-scale fluxes and mixing ratios of trace gases, including $\mathrm{CO}_{2}, \mathrm{O}_{3}$ and VOCs, had been measured at this original tower since its construction (Goldstein et al., 2000; Kurpius et al., 2002; Holzinger et al., 2005; Lee et al., 2005; Fares et al., 2010). The second tower was a new $18 \mathrm{~m}$ tall scaffolding tower built in 2007 and located $\sim 10 \mathrm{~m}$ north from the original tower. During the 2007 and 2009 summer intensive campaigns (BEARPEX 2007 and BEARPEX 2009), a full range of atmospheric trace gases and aerosols were measured by researchers from more than 10 institutions (Bouvier-Brown et al., 2009a; Wolfe et al., 2009; Smeets et al., 2009; Ren et al., 2010). Observations of vertical gradients and fluxes of BVOCs by PTR-QMS were made from 17 June (25 June for fluxes) to 29 July 2009 at the new tower. Electrical power was provided by a propane generator located approximately $125 \mathrm{~m}$ north of the new tower. Contamination from generator exhaust was observed occasionally at night when wind was slow and variable, but BVOC measurements were rarely affected, and we removed generator contaminated spikes such as benzene $(m / z 79)$. 


\subsection{PTR-QMS BVOC measurement}

\subsubsection{Instrument setup}

A PTR-QMS (Ionicon Analytik, Innsbruck, Austria) was set up to measure BVOC mixing ratios at multiple heights for determination of fluxes and vertical gradients. All measured compounds are listed by mass to charge ratios $(\mathrm{m} / \mathrm{z})$ in Table 1. The principles of the PTR-QMS have been described in detail elsewhere (Lindinger et al., 1998; de Gouw and Warneke, 2007). Briefly, the PTR-QMS is a chemical ionization technique that uses hydronium ions $\left(\mathrm{H}_{3} \mathrm{O}^{+}\right)$to transfer a proton $\left(\mathrm{H}^{+}\right)$from water to the VOC of interest; thus, any VOC with a proton affinity higher than water is ionized in the instrument's drift tube, introduced into the quadrupole mass spectrometer and detected by the secondary electron multiplier (SEM). The same instrument has been employed for past measurements of fluxes and vertical gradients at Blodgett Forest (Holzinger et al., 2005; Lee et al., 2005) and also for a similar measurement setup in a citrus orchard (Fares et al., 2012).

Air sample inlet heights on the measurement tower are depicted in Fig. 1. During each hour, six gas sampling inlets were used. One sampling inlet and a 3-D sonic anemometer (Campbell CSAT-3) were colocated at the top of the tower $(17.8 \mathrm{~m}$, about twice the canopy height) to measure flux by EC during the first 30 min of each hour. During second $30 \mathrm{~min}$ of every hour the other five inlets were sampled sequentially to measure vertical gradients above and within the forest canopy for $6 \mathrm{~min}$ at each height $(17.8 \mathrm{~m}, 13.6 \mathrm{~m}$, $9.5 \mathrm{~m}, 5.7 \mathrm{~m}$, and $1.5 \mathrm{~m}$ ). In retrospect, this sampling strategy is not the optimal for averaging out all the turbulent variations in a 30 min period; thus, we recommend having more cycles through the five (or less) heights for future studies (e.g., for a $30 \mathrm{~min}$ period, measuring 3 cycles of 5 heights with $2 \mathrm{~min}$ at each height). All inlets were protected by identical Teflon filters (PFA holder, PTFE membrane, pore size $2 \mu \mathrm{m})$ to avoid contamination by particles in the air sample. Each inlet was plumbed to the PTR-QMS with identical $30 \mathrm{~m}$ lengths of PFA tubing (OD $6.35 \mathrm{~mm}$, ID $3.96 \mathrm{~mm}$ ). A sample flow of $10 \mathrm{~L} \mathrm{~min}^{-1}$ was maintained at all times through each sample tube to minimize residence time and any memory effects from previously sampled air, and to maintain a turbulent flow for the EC flux measurement. Nevertheless, potential tubing wall loss was expected, particularly for some sticky compounds such as sesquiterpenes; see Bouvier-Brown et al. (2009a), who reported this issue. The Teflon filters were replaced every week and no signal differences for any measured compounds were observed after changing the filters. The PTR-QMS sequentially subsampled $\sim 0.6 \mathrm{~L} \mathrm{~min}^{-1}$ from each inlet, and was maintained at an $\mathrm{E} / \mathrm{N}$ (electric field to buffer gas number density) ratio of $139 \mathrm{Td}$ by adjusting drift tube pressure, temperature, and voltage to $200 \mathrm{~Pa}, 50^{\circ} \mathrm{C}$, and $604 \mathrm{~V}$, respectively. The reaction time in the drift tube was $100 \mu$ and the count rate of $\mathrm{H}_{3} \mathrm{O}^{+} \mathrm{H}_{2} \mathrm{O}$ ions (water clusters)

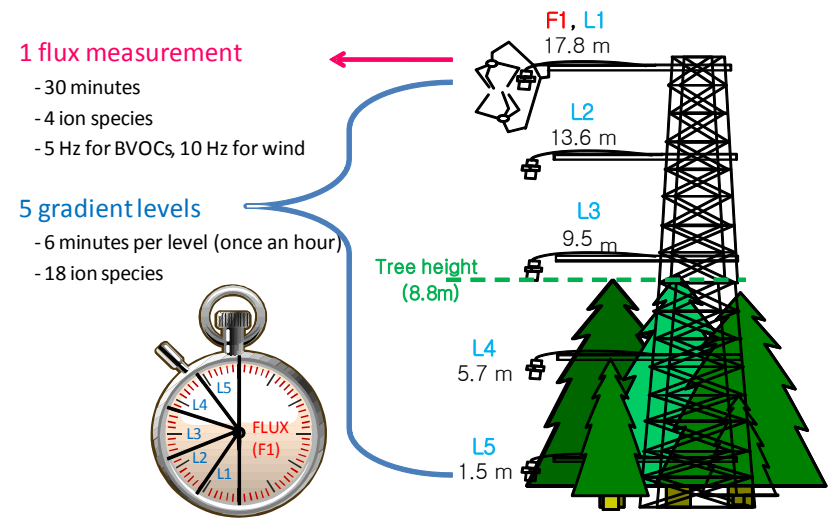

Fig. 1. Inlet configuration and sampling schedule on the $18 \mathrm{~m}$ tall tower during BEARPEX 2009. The PTR-MS sampled from an inlet $(\mathrm{F} 1)$ at $17.8 \mathrm{~m}$ colocated with a 3-dimensional sonic anemometer during the first $30 \mathrm{~min}$ of each hour for eddy covariance flux measurements, then sampled sequentially from five inlets (L1-L5) positioned at 17.8, 13.6, 9.5, 5.7, and $1.5 \mathrm{~m}$ above ground during the next $30 \mathrm{~min}$ to measure vertical gradients. Mean tree height was $8.8 \mathrm{~m}$.

was less than $3 \%$ of the count rate of $\mathrm{H}_{3} \mathrm{O}^{+}$ions. The $\mathrm{H}_{3} \mathrm{O}^{+}$ reactant ion was kept in the range $8 \pm 2 \times 10^{6}$ counts s $^{-1}$.

\subsubsection{Measurement calibration}

Calibrations were performed by dynamic dilution of gravimetrically mixed gas-phase standards (Apel \& Riemer, USA), including 2.2-5.1 ppmv of methanol, acetaldehyde, acetone, isoprene, methyl-vinyl-ketone, benzene, $\alpha$-pinene, $d$-limonene, and $\Delta$-3-carene into zero air at ambient humidity levels. Zero air was created by passing sampled ambient air through a stainless steel tube filled with platinumcoated quartz wool (Shimadzu) heated to $350^{\circ} \mathrm{C}$, catalytically removing VOCs from the sample. This zero air was directly measured to determine instrumental background counts twice daily (02:30-02:40 and 15:00-15:10 PST), and no significant difference between daytime and nighttime background was observed. Calibrations were also done twice a day for 20 min each after background measurement by diluting with purified air to concentrations of $40-100 \mathrm{ppbv}$. In order to check linearity of calibration curves at different concentrations of standard gases and compare them to the twice daily calibrations, we also performed 5-level multipoint calibrations using the same standard gas cylinder used for regular base calibration, every time before and after instrument and site maintenance activities during the campaign, such as optimizing the PTR-QMS SEM voltage and shutting down the electrical generator for oil changes. Measured mixing ratios from before-and-after calibration curves were in very good agreement for all compounds, with maximum difference within $6 \%$, and a minimum $R$-square of 0.98 . To determine mixing ratios of masses for which standard gases were not available, we calculated normalized 
Table 1. Mixing ratio and flux information for 18 selected ion species.

\begin{tabular}{|c|c|c|c|c|c|}
\hline Compounds & $\begin{array}{r}\text { Mass/ } \\
\text { charge } \\
(m / z)\end{array}$ & $\begin{array}{l}\text { Empirical } \\
\text { molecular formulae } \\
\text { (protonated mass) }\end{array}$ & $\begin{array}{l}\text { Detection } \\
\text { limit } \\
\text { [ppbv] }\end{array}$ & $\begin{array}{l}\text { Mixing ratio } \\
24 \text { h-mean } \\
(\text { day/night })^{\mathrm{a}} \\
{[\text { nmol mol }}\end{array}$ & $\begin{array}{l}\text { Flux } \\
24 \mathrm{~h}-\text { mean } \\
(\text { day) } \\
{\left[\mathrm{mg} \mathrm{C} \mathrm{m}^{-2} \mathrm{~h}^{-1}\right]}\end{array}$ \\
\hline Methanol & 33 & $\mathrm{CH}_{3} \mathrm{OHH}^{+}$ & $0.53 \pm 0.09$ & $16(13 / 16)$ & $0.18(0.48)$ \\
\hline Acetonitrile & 42 & $\mathrm{C}_{2} \mathrm{H}_{3} \mathrm{NH}^{+}$ & $0.05 \pm 0.01$ & $0.15(0.16 / 0.15)$ & $0.003(0.008)$ \\
\hline Acetaldehyde & 45 & $\mathrm{C}_{2} \mathrm{H}_{4} \mathrm{OH}^{+}$ & $0.21 \pm 0.04$ & $1.9(1.6 / 2.4)$ & $0.038(0.104)$ \\
\hline Acetone & 59 & $\mathrm{C}_{3} \mathrm{H}_{6} \mathrm{OH}^{+}$ & $0.14 \pm 0.03$ & $3.6(3.5 / 4)$ & $0.073(0.18)$ \\
\hline $\mathrm{MBO}^{\mathrm{b}}+$ isoprene & 69 & $\mathrm{C}_{5} \mathrm{H}_{8} \mathrm{H}^{+}\left(\mathrm{C}_{5} \mathrm{H}_{10} \mathrm{OH}^{+}\right)^{\mathrm{c}}$ & $0.38 \pm 0.12$ & $4.2(5.6 / 2.1)$ & $0.90(2.51)$ \\
\hline $\mathrm{MVK}+\mathrm{MACR}^{\mathrm{d}}$ & 71 & $\mathrm{C}_{4} \mathrm{H}_{6} \mathrm{OH}^{+}$ & $0.12 \pm 0.04$ & $1.2(1.5 / 1.3)$ & $0.013(0.019)$ \\
\hline Benzene & 79 & $\mathrm{C}_{6} \mathrm{H}_{6} \mathrm{H}^{+}$ & $0.04 \pm 0.01$ & $0.071(0.059 / 0.083)$ & $0.001(0.003)$ \\
\hline Monoterpenes & 81,137 & $\mathrm{C}_{6} \mathrm{H}_{8} \mathrm{H}^{+}, \mathrm{C}_{10} \mathrm{H}_{16} \mathrm{H}^{+}$ & $0.05 \pm 0.01$ & $1.1(0.6 / 1.3)$ & $0.2(0.46)$ \\
\hline Hexanal, hexenols & 83 & $\mathrm{C}_{6} \mathrm{H}_{10} \mathrm{H}^{+}$ & $0.06 \pm 0.01$ & $0.14(0.12 / 0.16)$ & $0.010(0.023)$ \\
\hline Hexenals & 99 & $\mathrm{C}_{6} \mathrm{H}_{10} \mathrm{OH}^{+}$ & $0.04 \pm 0.01$ & $0.16(0.15 / 0.18)$ & $0.012(0.031)$ \\
\hline Unknown OVOCs & 111 & $\begin{array}{l}\mathrm{C}_{8} \mathrm{H}_{14} \mathrm{H}^{+}, \mathrm{C}_{6} \mathrm{H}_{6} \mathrm{O}_{2} \mathrm{H}^{+} \\
\mathrm{C}_{7} \mathrm{H}_{10} \mathrm{OH}^{+}\end{array}$ & $0.02 \pm 0.02$ & $0.026(0.02 / 0.029)$ & $0.003(0.006)$ \\
\hline Unknown OVOCs & 113 & $\begin{array}{l}\mathrm{C}_{8} \mathrm{H}_{16} \mathrm{H}^{+}, \mathrm{C}_{7} \mathrm{H}_{12} \mathrm{OH}^{+}, \\
\mathrm{C}_{6} \mathrm{H}_{8} \mathrm{O}_{2} \mathrm{H}^{+}, \mathrm{C}_{5} \mathrm{H}_{4} \mathrm{O}_{3} \mathrm{H}^{+}\end{array}$ & $0.02 \pm 0.02$ & $0.15(0.18 / 0.15)$ & $0.0001(-0.0001)$ \\
\hline Nopinone & 139 & $\mathrm{C}_{9} \mathrm{H}_{14} \mathrm{OH}^{+}$ & $0.02 \pm 0.02$ & $0.056(0.046 / 0.071)$ & $0.006(0.016)$ \\
\hline Methyl chavicol & 149 & $\mathrm{C}_{10} \mathrm{H}_{12} \mathrm{OH}^{+}$ & $0.02 \pm 0.02$ & $0.099(0.064 / 0.084)$ & $0.015(0.038)$ \\
\hline Pinonaldehyde & 151 & $\mathrm{C}_{10} \mathrm{H}_{14} \mathrm{OH}^{+}$ & $0.02 \pm 0.02$ & $0.021(0.017 / 0.023)$ & $0.002(0.004)$ \\
\hline $\begin{array}{l}\text { Linalool, } \\
\text { unknown OVOCs }\end{array}$ & 155 & $\begin{array}{l}\mathrm{C}_{10} \mathrm{H}_{18} \mathrm{OH}^{+} \\
\mathrm{C}_{9} \mathrm{H}_{14} \mathrm{O}_{2} \mathrm{H}^{+}\end{array}$ & $0.02 \pm 0.02$ & $0.015(0.016 / 0.017)$ & $0.0007(0.003)$ \\
\hline Sesquiterpenes & 205 & $\mathrm{C}_{15} \mathrm{H}_{24} \mathrm{H}^{+}$ & $0.03 \pm 0.03$ & $0.095(0.072 / 0.098)$ & $0.028(0.06)$ \\
\hline
\end{tabular}

${ }^{a}$ Daytime and nighttime means are for hours 10:00-14:00 and 22:00-02:00 PST, respectively.

b 2-Methyl-3-butene-2-ol.

${ }^{c}$ Parent MBO ion in parenthesis. MBO main fragment ion is the same as isoprene parent ion.

d Sum of methyl vinyl ketone and methacrolein.

sensitivities (counts/concentration) based on calculated proton transfer reaction rate coefficients and the instrumentspecific transmission curve (de Gouw and Warneke, 2007). This curve was determined for $\mathrm{m} / \mathrm{z} 33$ to 219 using a gas standard mixture (methanol, acetonitrile, acetaldehyde, acetone, methacrolein, benzene, toluene, xylene, trifluorobenzene, bromobenzene, trichlorobenzene, and iodotoluene) at concentrations of $100 \mathrm{ppb}$ (Apel \& Riemer, USA). The transmission test was conducted along with each multipoint calibration. PTR-QMS signal at $m / z 69$ is the sum of a fragment of 2-methyl-3-butene-2-ol plus the parent mass of isoprene ( $\mathrm{MBO}+$ isoprene). Calibration of the mixing ratio for this mass was achieved by scaling the PTR-QMS measurement to equal the sum of MBO + ISOP measured simultaneously by gas chromatography-flame ionization detector (GCFID) (C. Park and G. Schade group, Texas A\&M University, correlation coefficient; slope $1, R^{2} 0.73$ ). For monoterpenes (MTs), the parent ion is observed at $m / z 137$ and the most abundant fragment occurs at $m / z 81$. The signal intensity was higher at $m / z 81$ than $m / z 137$ because of higher transmission efficiency. Thus, $m / z 81$ was used for total monoterpene EC flux measurements and calibrated by using a mixed monoterpene (alpha-pinene, 3-carene, and $d$-limonene) standard gas. The sum of $m / z 81$ and 137 was used for vertical gradient measurement. Comparison between the monoterpene concentrations from the EC flux inlet determined on $\mathrm{m} / \mathrm{z} 81$ with the vertical gradient inlet at the same height $(17.8 \mathrm{~m})$ for the adjacent $30 \mathrm{~min}$ period determined on the sum of $m / z 81+137$ showed good agreement (slope $0.95, R^{2}$ $0.84)$. Measurement accuracy for all compounds included in the calibration gas standard cylinder was better than $\pm 20 \%$. For all other compounds the concentration was estimated using the collision rate constant, which should equal the reaction rate constant within $\pm 30 \%$ (Holzinger et al., 2005).

\subsection{Disjunct eddy covariance flux measurements}

Fluxes of four BVOC masses $(m / z 33,69,81$, and 113) were measured using the disjunct eddy covariance method. Mixing ratios were measured with dwell time of $0.2 \mathrm{~s}$ per mass ( $5 \mathrm{~Hz}$ measurement resolution, $\sim 0.8 \mathrm{~s}$ per a cycle), resulting in 2120 measurement cycles per $30 \mathrm{~min}$ flux period. Wind speed and temperature signals from 3-D sonic anemometer were recorded on a datalogger (Campbell Scientific CR-23x) at $10 \mathrm{~Hz}$. For each $30 \mathrm{~min}$ flux measurement period, horizontal and vertical wind vectors were rotated according to a planar fit technique (Wilczack et al., 2001). Individual lag times for each $30 \mathrm{~min}$ flux period were determined by finding the time point with the maximum cross-correlation coefficient of 


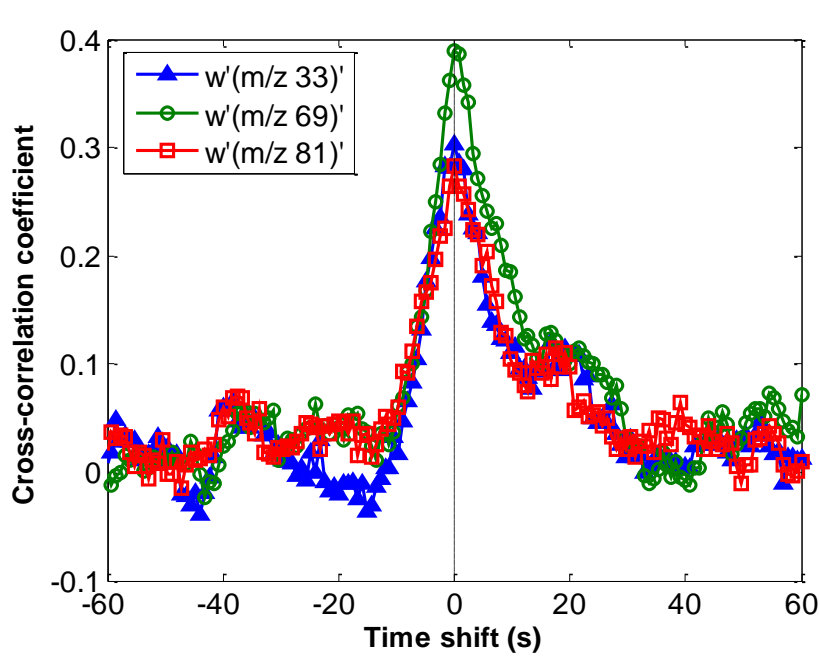

Fig. 2. Cross correlation of vertical wind speed $(w)$ and volume mixing ratios for 3 ion species $(\mathrm{m} / \mathrm{z} 33,69$, and 81) at 14:00-14:30 PST on 18 July 2009. Lag time corrections between vertical wind speed and volume mixing ratio of $X$ seconds have been applied to these data.

vertical wind speed and BVOC mixing ratios in $\pm 60 \mathrm{~s}$ time windows. Lag times accounted for changes in clock synchronization between the PTR-QMS computer and the data logger recording wind data, and for sampling flow and instrument response times. In cases in which a clear covariance peak was not observed, particularly at nighttime when vertical turbulence was low, we interpolated lags between the two nearest points having strong covariance peaks. The lag time correction has been applied to these data, and we used the same lag time for all masses. After the lag time correction, Fig. 2 shows the cross correlations between vertical wind speed and each BVOC $(m / z 33,69$, and 81$)$ by time peak at $0 \mathrm{~s}$, indicating all BVOCs measured have the same lag times in one flux period.

Fluxes for 4 mass to charge ratios of interest $(m / z 33$, 69, 81 and 113, but we do not report $\mathrm{m} / z 113$ fluxes in this paper) were determined according to the virtual (continuous flow) disjunct eddy covariance method (Rinne et al., 2001; Karl et al., 2002), which can be regarded as a variant of the EC method. The vertical fluxes of BVOCs were calculated as the mean covariance between deviations of the vertical wind speed and each BVOC mixing ratio for a flux period (30 min); thus, we used a subsample of the vertical wind speed $(w)$ data after subtracting the lag time $(\Delta t)$ due to slower data acquisition frequency for each measured BVOC $(5 \mathrm{~Hz})$ than the wind $(10 \mathrm{~Hz})$. Flux was determined according to the following equation:

$F_{\mathrm{EC}}=\frac{\rho}{N} \sum_{i=1}^{N} w^{\prime} \cdot c^{\prime}(i)$, where $\rho$ is the air density $\left(\mathrm{mol} \mathrm{m}^{-3}\right), w^{\prime}$ is the instantaneous deviation of the vertical wind speed from its average, $c^{\prime}$ is that of the BVOC mixing ratio $\left(\mathrm{nmol} \mathrm{mol}{ }^{-1}\right)$ (i.e., $w^{\prime}=w-$ $\bar{w}, c^{\prime}=c-\bar{c}$ ), and $N$ is the total number of data points in the measurement period.

The EC method requires that the estimated fluxes within an analyzed period are stationary. To test for stationarity, we divided each $30 \mathrm{~min}$ flux period into 5 segments $(6 \mathrm{~min}$ data for each), calculated the EC flux for each segment, and compared the average to the EC flux for the full $30 \mathrm{~min}$ period. We rejected fluxes for any times when the segmental flux was not within $\pm 30 \%$ of the full 30 min flux (Lee et al., 2004; Foken and Wichura, 1996). More than $92 \%$ of daytime (09:0015:00 PST) and $86 \%$ of nighttime (21:00-03:00 PST) data passed these filtering criteria.

We tested for potential flux errors from several known sources. Spectral attenuation by sensor separation and inlet dampening effects were estimated using transfer functions described elsewhere in detail (Moore, 1986; Massman, 1991), and these had less than $1 \%$ effect on our measured EC fluxes. Loss of flux signal can arise from inadequate sensor response time and can be estimated as

$\frac{F_{\text {meas }}}{F_{\text {true }}}=\frac{1}{1+\left(2 \pi \cdot f_{\mathrm{m}} \cdot \tau_{c}\right)^{\alpha}}$,

where $F_{\text {meas }}$ is the measured flux, $F_{\text {true }}$ is the true flux (nonattenuated flux), $f_{\mathrm{m}}$ is the frequency of the peak at which the frequency weighted cospectrum maximizes, $\tau_{c}$ is the firstorder response time of the instrument, and $\alpha$ is $7 / 8$ for neutral and unstable stratification within the surface layer and 1 for stable condition (Horst, 1997). Based on this consideration, if we consider only daytime (09:00 to 17:00 PST) fluxes with $\tau_{c}$ of $1 \mathrm{~s}$ and $f_{\mathrm{m}}$ of ranges between 0.01 and 0.02 for daytime, fluxes could be underestimated by $8-14 \%$. This is a similar range to what was estimated during a previous study at this site (Lee et al., 2005), and we did not correct flux data for this effect.

The storage of BVOC emission between the ground and the flux measurement height can be important during times when the air is in a stable stratified condition or turbulent mixing is weak; thus, plant or soil emissions in such periods may not be well represented in the above canopy flux measurements (Rummel et al., 2007; Wolfe et al., 2009). We incorporated this into our flux calculation using

$F=F_{\mathrm{EC}}+\frac{\partial}{\partial t} \int_{0}^{h}[\mathrm{BVOC}](z) \mathrm{d} z$,

where $z$ and $h$ are the height of vertical gradient and EC flux measurements, respectively, and [BVOC] is the mixing ratio of each compound. The storage term for methanol $(m / z 33), \mathrm{MBO}+$ isoprene $(m / z 69)$, and monoterpenes $(\mathrm{m} / \mathrm{z} 81)$ contributed $57 \%, 8 \%$, and $65 \%$, respectively, compared to EC flux in the morning hours 06:00-08:00 PST, and were extremely small or negligible (less than $0.7 \%$ ) 


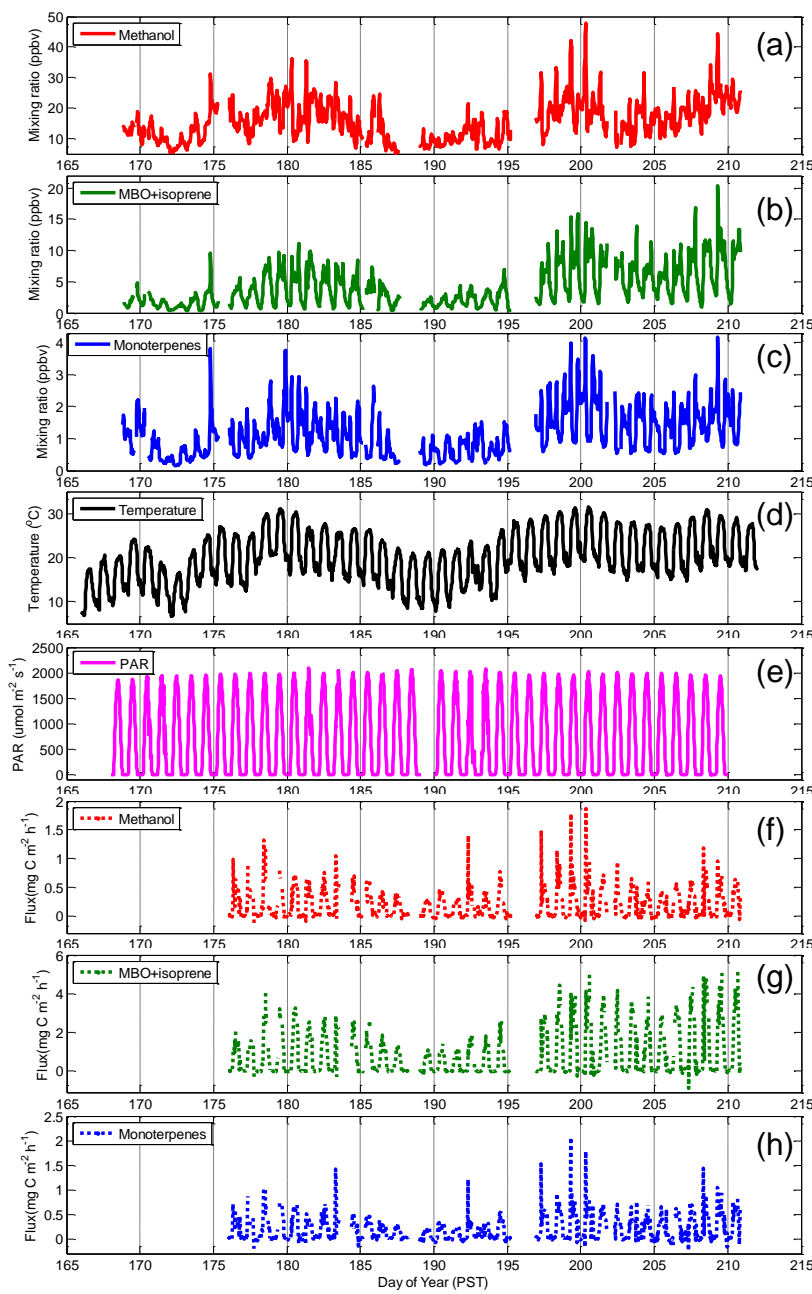

Fig. 3. Volume mixing ratio time series of (a) methanol, (b) $\mathrm{MBO}+$ isoprene and (c) monoterpenes, (d) air temperature, (e) photosynthetically active radiation (PAR), and EC fluxes of (f) methanol, (g) $\mathrm{MBO}+$ isoprene and (h) monoterpenes. All data are averaged on an hourly basis.

during the daytime (08:00-18:00 PST) and at nighttime (20:00-06:00 PST).

\subsection{Vertical gradient measurements}

Vertical gradients were measured for 18 masses, as listed in Table 1. These masses were chosen to observe the most important compounds at this site based on previous BVOC observations performed by gas chromatography (GC) and PTRQMS from 1997 to 2007 (Lamanna and Goldstein, 1999; Schade et al., 2000; Holzinger et al., 2005; Bouvier-Brown et al., 2009a). Using multiple ion detection mode in the PTRQMS software (Balzer QS 422), these masses were scanned for 14 cycles over 6 min for each height with a dwell time on each mass of $1 \mathrm{~s}$, except for $m / z 205$ for which we used a dwell time of $5 \mathrm{~s}$ to improve detection limits for this mass.
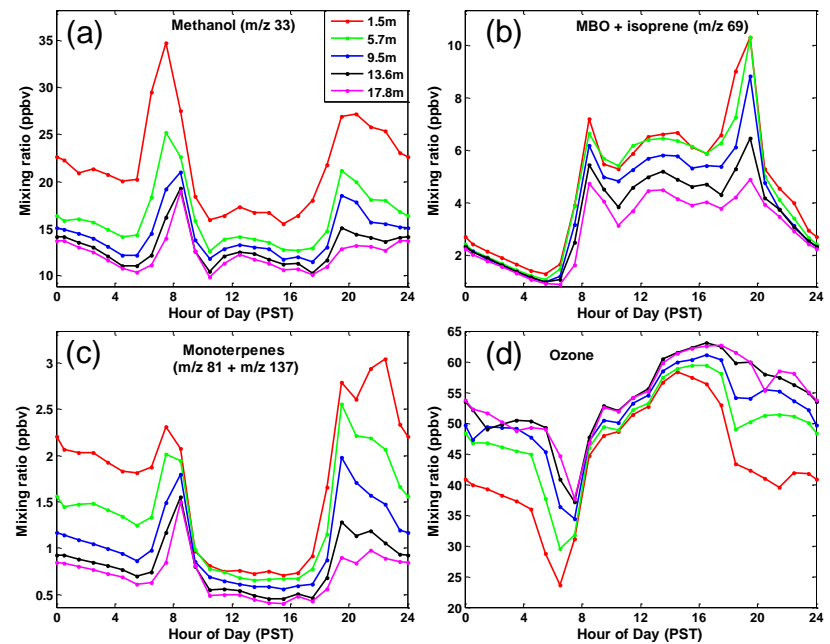

Fig. 4. Averaged diurnal cycles of vertical gradients for (a) methanol, (b) $\mathrm{MBO}+$ isoprene, (c) monoterpenes, and (d) ozone. Measurement heights are indicated in the legend (a).

The first 4 cycles after switching inlet heights were discarded, and data for the last 10 cycles for each height were used to compute hourly averaged data sets.

\section{Results}

\subsection{Concentration and vertical gradients}

Figure $3 \mathrm{a}-\mathrm{c}$ respectively show the full time series of volume mixing ratios for methanol $(\mathrm{m} / z 33), \mathrm{MBO}+$ isoprene $(m / z 69)$, and the sum of monoterpenes $(m / z 81+m / z$ 137), with mixing ratios averaged from all measurement heights. All these compounds appear dependant on temperature, as shown in Fig. 3d. Methanol is most abundant, followed by $\mathrm{MBO}+$ isoprene, acetone, acetaldehyde, MVK + MACR, and total monoterpenes, as summarized in Table 1. Figure 4 presents the average diurnal profile of vertical gradients for methanol, $\mathrm{MBO}+$ isoprene, and monoterpenes in addition to ozone. Mixing ratios of all these BVOCs decrease with increased inlet height, indicating emission from the forest, and this higher mixing ratio at lower heights within the canopy is due to more biomass near the surface. In contrast, the ozone gradient is inversed, suggesting active BVOC oxidation processes and/or stomatal uptake by plants existing within the canopy (Kurpius and Goldstein, 2003; Fares et al., 2010). Mixing ratios of these 3 BVOCs were the highest in the morning and evening. This is mainly due to breakup of the atmospheric boundary layer (ABL) in the morning, while the ABL lowers in the evening coupled with stomatal opening/closing by plant circadian cycle, with the peaks corresponding to the transition time of ABL height, as observed by Choi et al. (2011). After these morning peaks, mixing ratios decrease because of dilution of emissions into 

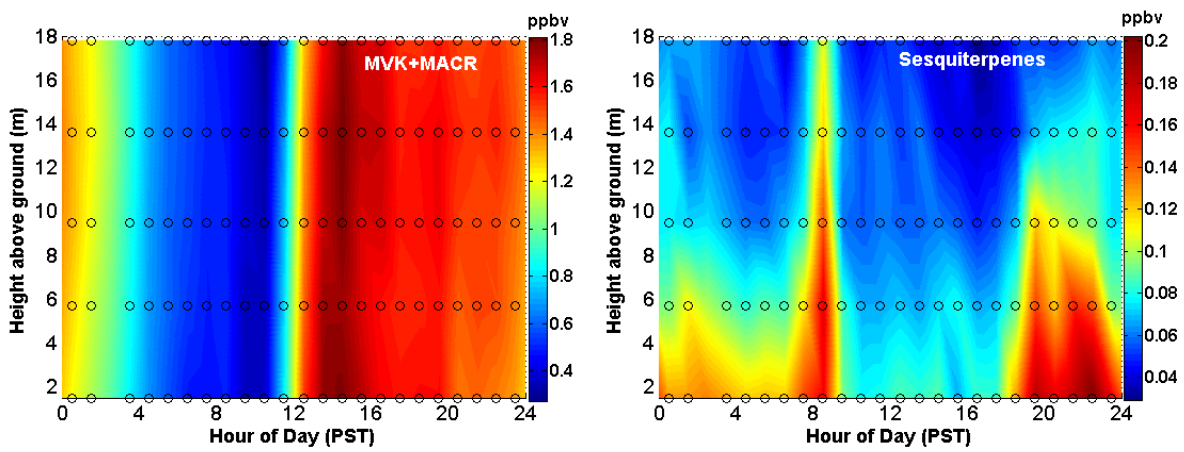

Fig. 5. Mean vertical gradient diurnal patterns for MVK + MACR (left) and sesquiterpenes (right). Color represents interpolated concentration gradients with actual measurement timing and vertical positions indicated by open circles.

a larger mixing layer and faster oxidation of BVOCs during daytime from high daytime ozone mixing ratios, which were observed up to $100 \mathrm{ppbv}$. High mixing ratios and strong gradients for methanol and monoterpenes for nighttime reflect temperature-dependent emission, but $\mathrm{MBO}+$ isoprene emissions are known to be temperature and light dependent (Harley et al., 1998; Schade et al., 2000; Guenther et al., 2006). A distinctively higher methanol mixing ratio near the surface (1.5 m height) suggests that soil, leaf litter, and/or understory plant emission may significantly contribute to methanol emission at this site (Schade and Goldstein, 2001). The same diurnal pattern has been shown previously at the site (Holzinger et al., 2005; Bouvier-Brown et al., 2009a). In addition to these compounds, Fig. 5 shows vertical gradients and diurnal cycles for MVK + MACR and sesquiterpenes. MVK and MACR are well known as major secondary products from the atmospheric oxidation of isoprene, but isoprene emission from this site is minor without strong vertical gradients observed during daytime, meaning that local isoprene emissions and MVK + MACR production are small. The maximum mixing ratio peak showed around hours 15:00-16:00 PST. This pattern is because the air parcel from oak forest, which is a high isoprene emitter, undergoes oxidation of isoprene and is transported to the site with isoprene oxidation products (i.e., MVK and MACR), this result being consistent with a previous study (Dreyfus et al., 2002). Sesquiterpenes are not easy to measure in the ambient air because (1) they exist at low concentrations; (2) many of them have a very short lifetime; and (3) their large molecule structure and low volatility make them harder to sample through the Teflon tubing due to stickiness. However, we successfully measured sesquiterpenes by setting dwell time of mass scanning to $5 \mathrm{~s}$ and having a fast and continuous sample flow in the tube (residence time of $\sim 2.3 \mathrm{~s}$ ); nevertheless, the measurement of sesquiterpenes are still highly uncertain due to their low transmission efficiency passing through PTR-QMS quadrupole lens and losses in the sampling inlet and instrument's internal inlet surfaces. However, vertical gradients of sesquiterpenes showed a very similar pattern to monoterpenes, indicating emission patterns are similar.

An averaged daytime (10:00-17:00 PST) sesquiterpene mixing ratio of $84 \mathrm{ppt}$ at $1.5 \mathrm{~m}$ above the ground was observed. This is about twice greater than GC measurements conducted in the similar season during BEARPEX 2007 (Bouvier-Brown et al., 2009a), but the GC data included only 6 speciated sesquiterpenes, suggesting that additional sesquiterpene species could be emitted in this ponderosa pine forest site.

\subsection{Eddy covariance fluxes}

The full time series of fluxes for methanol $(\mathrm{m} / \mathrm{z} 33)$, MBO + isoprene $(m / z 69)$ and monoterpenes $(m / z ~ 81)$ are depicted in Fig. $3 \mathrm{f}-\mathrm{h}$. Generally, fluxes of all 3 species show strong temperature dependent emission throughout the measurement period. For example, low emissions were observed around day 190 when temperatures were relatively low, with high emissions observed during the high temperatures of day 200. Similar diurnal cycles between the three masses are also observed, with emissions starting at sunrise, increasing as air temperature and light intensity increased during daytime, and stopping after sunset. Based on the vertical gradient for methanol and monoterpenes shown in Fig. 4a and b, nighttime emissions seem to occur, but no significant fluxes were observed due to lower vertical turbulent mixing.

The sum of MBO and isoprene is quantified as $m / z 69$; however, $\mathrm{MBO}$ is the main contributor to $m / z 69$ fluxes since isoprene emission at this site is minor, as described above. Therefore, $\mathrm{MBO}$ is the predominant emission from the site with a day average $\sim 0.90 \mathrm{mg} \mathrm{C} \mathrm{m}^{-2} \mathrm{~h}^{-1}$, and is about 5 times greater than either methanol or monoterpene emissions. 


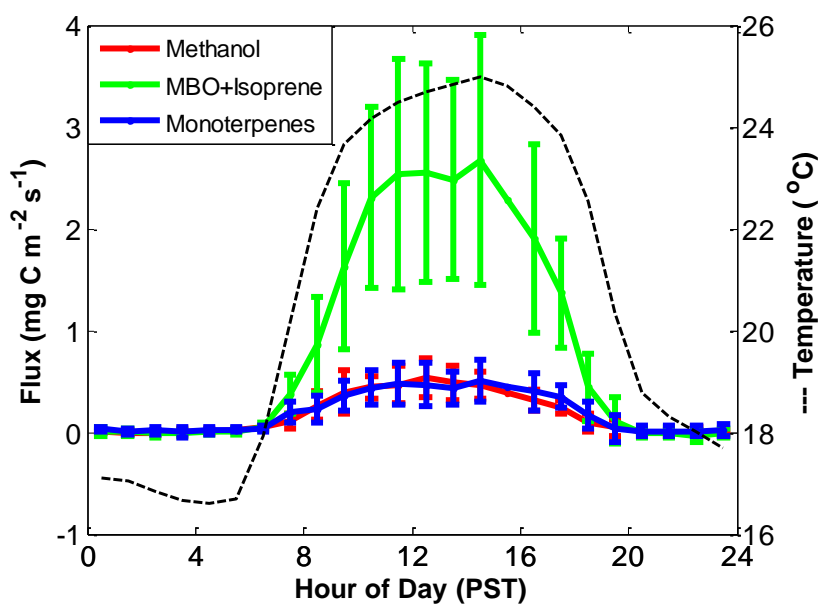

Fig. 6. Mean diurnal variation of air temperature (dashed black line) and fluxes for methanol (red line), $\mathrm{MBO}+$ isoprene (green line), and monoterpenes (blue line). Error bars denote standard deviations of all measurements at the respective hour of the day.

\section{Analysis and discussion}

\subsection{Flux estimation by flux-gradient relationship ( $K$-theory)}

Fluxes of the other 14 species selected for vertical gradients were not measured because the PTR-QMS can measure EC fluxes only for a few compounds at a time due to limitations of the quadrupole mass filter. Instead, we used a fluxgradient similarity approach, also known as $K$-theory, for determining fluxes of all compounds not measured by the EC method (Goldstein et al., 1996, 1998). The trace gas flux $(F)$ is assumed to be proportional to the time-averaged mixing ratio gradient $(\mathrm{d} C / \mathrm{d} z)$ above the forest for intervals longer than the timescale of the slowest significant turbulence events:

$F=-K \frac{\mathrm{d} C}{\mathrm{~d} z}$

where $K$ is the eddy diffusivity and is determined for each hour of measurements. In previous studies that used $K$-theory for quantifying VOC fluxes, $K$ was computed from flux and vertical gradient measurements of carbon dioxide $\left(\mathrm{CO}_{2}\right)$, water $\left(\mathrm{H}_{2} \mathrm{O}\right)$, or sensible heat, and then multiplied by VOC vertical gradients (Goldstein et al., 1996, 1998; Schade et al., 2000). However, this approach requires another sensor to measure $\mathrm{CO}_{2}, \mathrm{H}_{2} \mathrm{O}$, and/or sensible heat. In order to overcome this, we derived $K$ directly from BVOC EC fluxes and vertical gradients $\left(K_{m 33}\right.$ for methanol, $K_{m 69}$ for $\mathrm{MBO}+$ isoprene, and $K_{m 81}$ for monoterpenes) measured by one instrument (i.e., PTR-QMS), and we further derived a universal $K\left(K_{\text {univ }}\right)$ by averaging $K$ computed from the three
Table 2. Comparison of $K$ s calculated from $m / z$ 33, 69 and 81 .

\begin{tabular}{lccc}
\hline$K_{\mathrm{y}}$ vs. $K_{\mathrm{X}}$ & Slope $\left(K_{\mathrm{y}} / K_{\mathrm{x}}\right)$ & $R^{2}$ & No. of samples \\
\hline$K_{m 33}$ vs. $K_{m 69}$ & 0.96 & 0.63 & 168 \\
$K_{m 69}$ vs. $K_{m 81}$ & 0.94 & 0.57 & 169 \\
$K_{m 81}$ vs. $K_{m 33}$ & 0.93 & 0.62 & 193 \\
\hline
\end{tabular}

different BVOCs according to the following equation:

$$
\begin{aligned}
K_{\text {univ }} & =\frac{\left(K_{m 33}+K_{m 69}+K_{m 81}\right)}{3} \approx \frac{-F_{m 33}}{\mathrm{~d} C_{m 33} / \mathrm{d} z} \\
& \approx \frac{-F_{m 69}}{\mathrm{~d} C_{m 69} / \mathrm{d} z} \approx \frac{-F_{m 81}}{\mathrm{~d} C_{m 81} / \mathrm{d} z} .
\end{aligned}
$$

To calculate $K$ for each $m / z$, we used gradient data from $17.8 \mathrm{~m}$ (mixing ratio data from EC flux measurements were used) and $9.5 \mathrm{~m}$ (gradient measurements), which were above the canopy, since concentration differentials between two upper heights $(17.8 \mathrm{~m}$ and $13.6 \mathrm{~m})$ were too low. With one instrument it is not possible to simultaneously measure mixing ratios for different heights, and one also needs to consider the time difference between flux and gradient measurements. Therefore all gradient data were interpolated to match the same time period as the flux measurements. In addition, data were not used if the gradient for an hour was too small to be detected reliably (less than twice standard deviation of zero air signal) since those values induce a large uncertainty in $K$, or if the gradient was inverted, e.g., a higher mixing ratio at $17.5 \mathrm{~m}$ than $9.5 \mathrm{~m}$ with upward flux. Based on these criteria, $75 \%$ for methanol, $51 \%$ for $\mathrm{MBO}+$ isoprene, and $77 \%$ for monoterpene data were used, with the vast majority of unused observations occurring at night. At least one to three $K$ values $\left(K_{m 33}, K_{m 69}\right.$, and/or $\left.K_{m 81}\right)$ were calculated for every hour, and averaged to a $K_{\text {univ }}$ of which was then applied to estimate fluxes for all compounds with measured vertical gradients. Figure 7 presents the diurnal variation of $K_{m 33}$, $K_{m 69}, K_{m 81}$, and $K_{\text {univ }}$. The pattern of $K$ is similar to the flux diurnal profile for most species with maxima during the day when vertical turbulent mixing is strongest. The three $K$ values $\left(K_{m 33}, K_{m 69}, K_{m 81}\right)$ agreed well with each other (within $7 \%$ by slope of scatter plots, Table 2). This indicates that the two sampling heights have similar footprint characteristics in terms of underlying vegetation and soil, and the different timescales in photooxidation processes for these 3 compounds do not significantly affect the calculation of $K$ at this site. To validate that $K_{\text {univ }}$ can be properly used to calculate fluxes for the other compounds, we applied $K_{\text {univ }}$ to vertical gradients of methanol, $\mathrm{MBO}+$ isoprene, and monoterpenes. Hourly fluxes computed by $K_{\text {univ }}$ were compared to direct EC flux measurements, and on average these agreed within $4 \%$ with $R$-square of higher than 0.83 for all three species (Fig. 8).

Fluxes of the other 14 species selected for vertical gradient measurement were determined by multiplying observed 


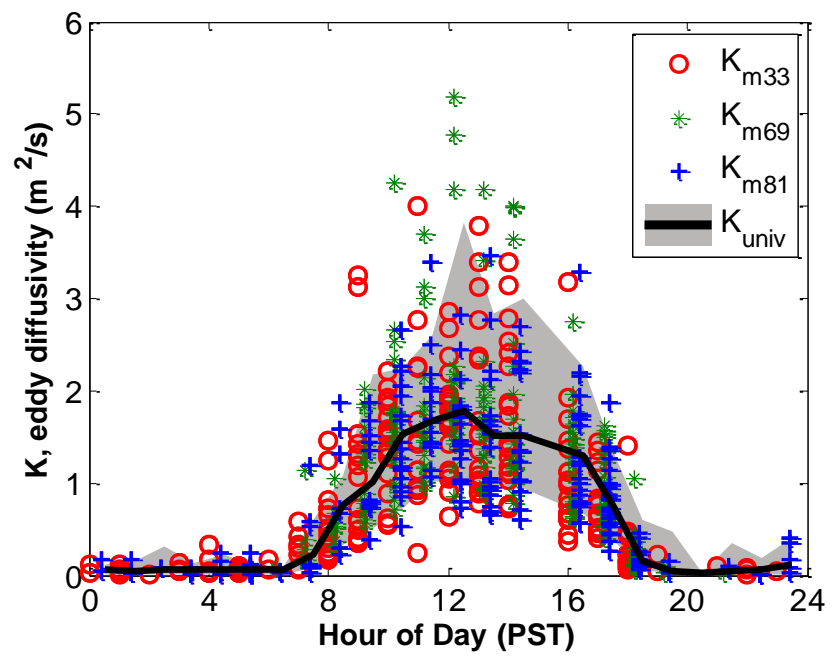

Fig. 7. The eddy diffusivity diurnal patterns calculated from measured fluxes and vertical gradients of methanol (red circles, $K_{m 33}$ ), $\mathrm{MBO}+$ isoprene (green asterisks, $K_{m 69}$ ), monoterpenes (blue pluses, $K_{m 81}$ ) and the mean universal $K$ (black line, $K_{\text {univ }}$ ) calculated according to Eq. (5). Shaded area denotes 10-90th percentile of data.

gradients with $K_{\text {univ }}$. Figure 9 shows the resultant diurnal flux cycles for 15 BVOC species, including methanol for reference. Daily average net fluxes are presented in Table 1. Among these 14 species, acetone $(\mathrm{m} / z$ 59) and acetaldehyde $(\mathrm{m} / \mathrm{z} 45)$ fluxes showed the most significant emissions throughout the day with maximum around noon of 0.21 and $0.12 \mathrm{mg} \mathrm{C} \mathrm{m}^{-2} \mathrm{~h}^{-1}$, respectively. After the noon peak, emission rates of both compounds decreased at hours 13:00-14:00 PST, indicating that active photochemical production/loss processes of VOC above the canopy may suppress the measurable flux strength of these compounds. This phenomenon was also observed in summer 1999 at the same site using a GC-REA (gas chromatography-relaxed eddy accumulation) system (Schade and Goldstein, 2001). Methyl chavicol $(m / z$ 149) and sesquiterpene $(m / z$ 205) emissions were also apparent with daytime maxima of 0.06 and $0.08 \mathrm{mg} \mathrm{C} \mathrm{m}^{-2} \mathrm{~h}^{-1}$, respectively. Low level emissions of acetonitrile $(m / z 42)$, hexanal and hexenols $(m / z 83)$, hexenal $(m / z$ 99), and $m / z 111$ (unidentified OVOCs) were observed with daytime maxima each below $0.05 \mathrm{mg} \mathrm{C} \mathrm{m}^{-2} \mathrm{~h}^{-1}$. Interestingly, some oxygenated BVOCs produced by photooxidation of terpenes or isoprene such as MVK + MACR ( $m / z, 71$ ), $m / z 113$ (unidentified OVOCs), $m / z 151$ (pinonaldehyde), and $m / z 155$ (linalool + unidentified OVOCs) were both emitted and deposited throughout the day, though the flux magnitudes were relatively small. This observation implies those compounds were produced by photooxidation within/above the canopy and were also deposited from the atmosphere to the ecosystem. We observed emission of nopinone $(m / z, 139)$ in the afternoon during hours 13:0015:00 PST. Nopinone is a main $\beta$-pinene plus $\mathrm{OH}$ oxidation

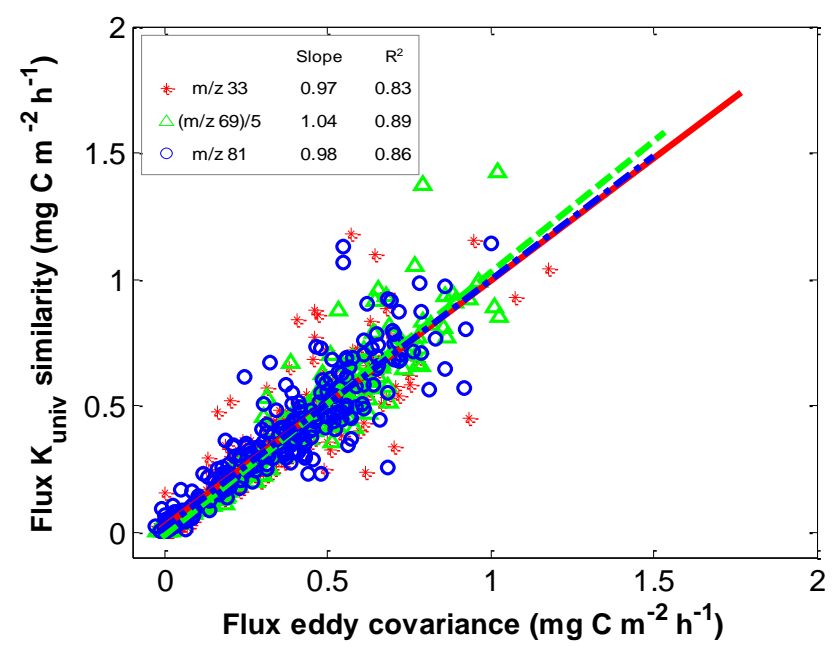

Fig. 8. Comparison between flux determined by the eddy covariance method and flux determined by the flux-gradient similarity method using the universal $K\left(K_{\text {univ }}\right)$ for methanol $(\mathrm{m} / z 33$, red asterisks), $\mathrm{MBO}+$ isoprene $(\mathrm{m} / \mathrm{z} 69$, green triangles), and monoterpenes $(\mathrm{m} / \mathrm{z}$ 81 , blue circles). The red, green, and blue lines are the best linear fit for methanol, $\mathrm{MBO}+$ isoprene, and monoterpenes, respectively.

product, and $\beta$-pinene is one of the most abundant monoterpene species at this site (Lee et al., 2005; Bouvier-Brown et al., 2009a). This observation of nopinone emission from the canopy with maximum in the afternoon is consistent with the daily maximum combination of light and temperatures driving both the $\beta$-pinene emissions and its oxidation by $\mathrm{OH}$ radicals. Hourly total and fractional BVOC fluxes for all measured species are presented in Fig. 10. A $24 \mathrm{~h}$ mean net total emission of $1.5 \mathrm{mg} \mathrm{C} \mathrm{m}^{-2} \mathrm{~h}^{-1}$ was estimated with a daytime (10:00-14:00 PST) average of $4.0 \mathrm{mg} \mathrm{C} \mathrm{m}^{-2} \mathrm{~h}^{-1}$. Emissions were dominated by $\mathrm{MBO}+$ isoprene $(61 \%$ of total, and almost exclusively MBO due to minimal isoprene emission at this site, as shown by Schade and Goldstein, 2001), followed by monoterpenes $(13 \%)$ and methanol $(12 \%)$. For the other compounds that were estimated by $K$-theory, acetone and acetaldehyde emissions were respectively $4.9 \%$ and $2.6 \%$ of the total emission, followed by sesquiterpenes $(1.9 \%)$, methyl chavicol (1.0\%), and low levels of emissions for the others (less than $1 \%$ for each). Though we did not observe substantial deposition fluxes, the maximum total deposition $\left(-0.015 \mathrm{mg} \mathrm{C} \mathrm{m}^{-2} \mathrm{~h}^{-1}\right)$ by 2 OVOCs $(\mathrm{m} / z 151$ and 155$)$ occurred at noontime.

\subsection{BVOC emission model}

To parameterize measured emissions with commonly used BVOC emission models, we categorized the observed emissions into species that are dependent on temperature versus dependent on both light and temperature. The emission of monoterpenes from this site is known from past observations to be mainly dependent on temperature (e.g., Schade and 


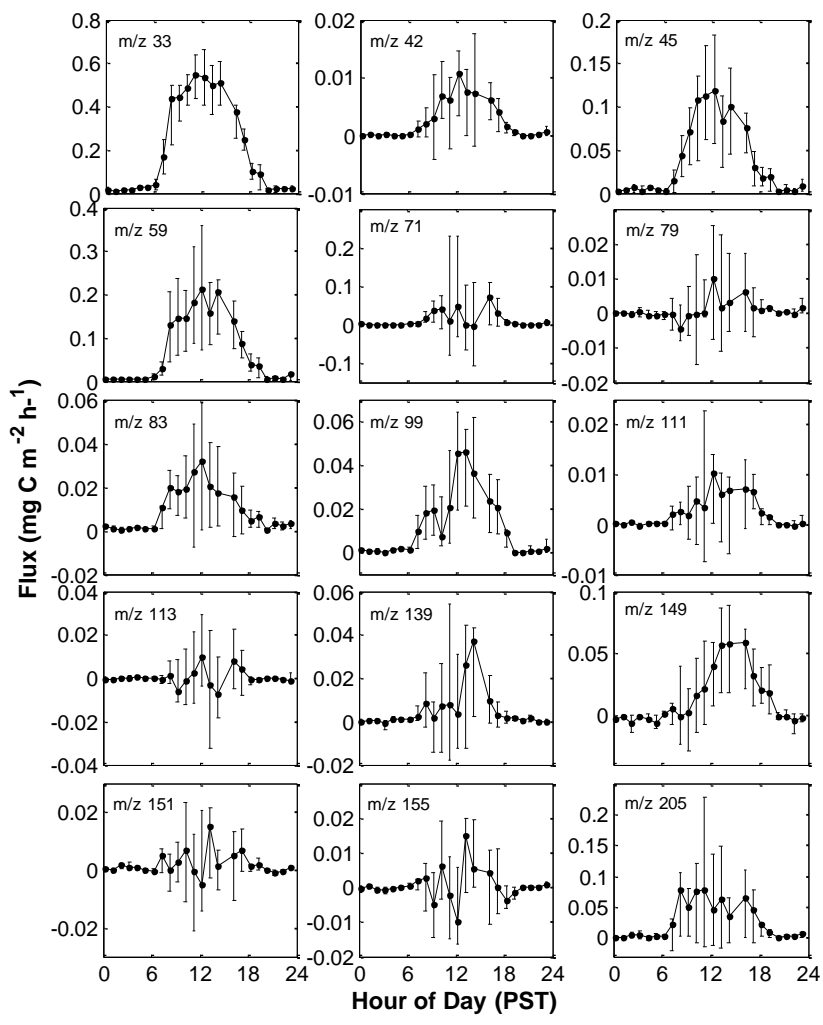

Fig. 9. Mean diurnal cycles of fluxes determined by the similarity method using the universal $K$ for 15 ion species observed. Vertical bars denote $25-75$ th percentile.

Goldstein, 2003), with a relationship that can be expressed as (Tingey, 1980; Guenther et al., 1993)

$E_{T}=\mathrm{BER}_{T} e^{\beta\left(T_{\mathrm{air}}-30\right)}$,

where $\mathrm{BER}_{T}$ is the basal emission rate at $30^{\circ} \mathrm{C}, \beta\left({ }^{\circ} \mathrm{C}^{-1}\right)$ is a temperature dependence coefficient, and $T_{\text {air }}\left({ }^{\circ} \mathrm{C}\right)$ represents the within-canopy air temperature. From our EC flux data, $\mathrm{BER}_{T}\left(0.6 \pm 0.14 \mathrm{mg} \mathrm{C} \mathrm{m}^{-2} \mathrm{~h}^{-1}\right.$, mean \pm standard deviation) was determined as the mean of data collected at the within-canopy air temperature range of $29-31^{\circ} \mathrm{C}$, and $\beta\left(0.12 \pm 0.01{ }^{\circ} \mathrm{C}^{-1}\right)$ was computed by inverting Eq. (6). Canopy-scale flux measurements previously reported from this site using PTR-QMS EC and GC-FID REA systems had ranges of $0.47-1.2 \mathrm{mg} \mathrm{C} \mathrm{m}^{-2} \mathrm{~h}^{-1}$ for $\mathrm{BER}_{T}$ and $0.06-$ $0.15^{\circ} \mathrm{C}^{-1}$ for $\beta$ (Schade and Goldstein, 2003; Lee et al., 2005; Holzinger et al., 2006; Bouvier-Brown et al., 2012), in good agreement with the results reported here.

In contrast to monoterpenes, MBO emissions are driven by both temperature and light intensity as described here (Harley et al., 1998; Schade and Goldstein, 2001):

$E_{T+L}=\mathrm{BER}_{T+L} \cdot \gamma_{L} \cdot \gamma_{T}$,

where $\mathrm{BER}_{T+L}$ represents the basal emission rate at standard condition (PAR of $1000 \mu \mathrm{mol} \mathrm{m}^{-2} \mathrm{~s}^{-1}$ and within-canopy air

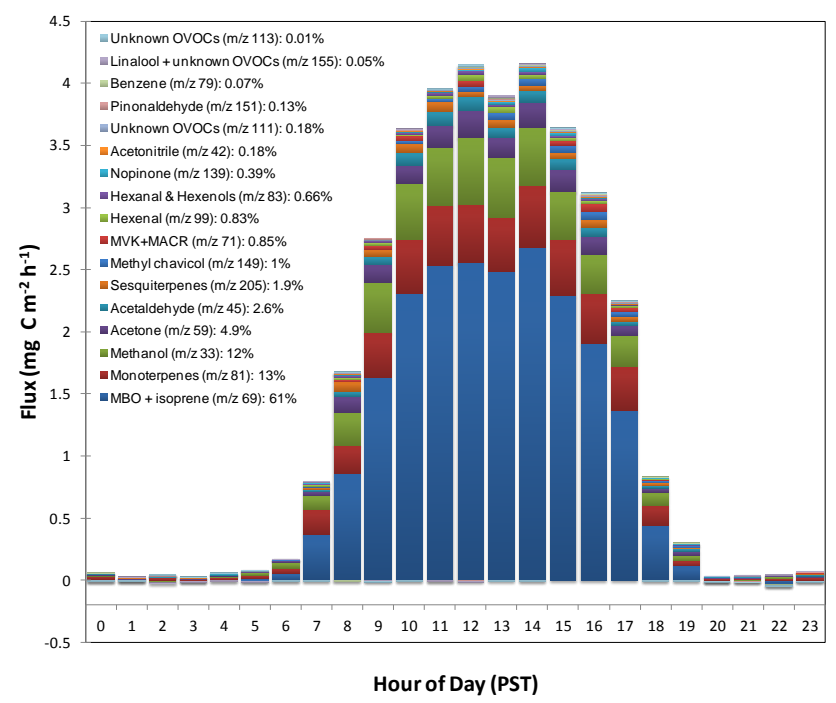

Fig. 10. Total hourly mean BVOC diurnal flux on a carbon mass basis shown as staged bar plots with contributions indicated for each of the 17 masses measured. The eddy covariance flux data were used for 3 masses $(m / z 33,69,81)$ and flux data calculated by fluxgradient similarity method were applied for the other 14 masses ( $m / z$ 42, 45, 59, 71, 79, 83, 99, 111, 113, 139, 149, 151, 155, 205). Largest fluxes are at the bottom. The percentages in the legend indicate contributions of individual compounds to the daily total emission.

temperature of $\left.30^{\circ} \mathrm{C}\right) \cdot \gamma_{\mathrm{L}}$ and $\gamma_{T}$ are respectively light emission activity factor and temperature emission activity factor, computed as follows:

$\gamma_{\mathrm{L}}=\alpha \cdot c \cdot\left(\frac{\mathrm{PAR}}{\sqrt{1+\alpha^{2} \cdot \mathrm{PAR}^{2}}}\right)$

$\gamma_{T}=E_{\mathrm{opt}}\left(\frac{C_{T 2} \cdot e^{\frac{\left(1 / T_{\mathrm{opt}}-1 / T\right)}{R} \cdot C_{T 1}}}{C_{T 2}-C_{T 1} \cdot\left(1-e^{\left.\frac{\left(1 / T_{\mathrm{opt}}-1 / T\right)}{R} \cdot C_{T 2}\right)}\right.}\right)$,

where $\alpha(=0.0011)$ and $c(=1.37)$ are empirical coefficients, $E_{\text {opt }}(=1.45)$ is the maximum normalized emission capacity, $T_{\mathrm{opt}}(=312 \mathrm{~K}$ by default $)$ is the temperature at which $E_{\text {opt }}$ occurs, $T$ is air temperature $(\mathrm{K}), R$ is the ideal gas constant $\left(=0.00831 \mathrm{~kJ} \mathrm{~mol}^{-1} \mathrm{~K}^{-1}\right)$, and $C_{T 1}\left(131 \mathrm{~kJ} \mathrm{~mol}^{-1}\right)$ and $C_{T 2}\left(154 \mathrm{~kJ} \mathrm{~mol}^{-1}\right)$ are the energies of deactivation and activation, respectively. All constants used were taken from Schade and Goldstein (2001). Based on this model, BER ${ }_{T+L}$ $\left(3.8 \pm 0.7 \mathrm{mg} \mathrm{C} \mathrm{m}^{-2} \mathrm{~h}^{-1}\right)$ was derived from our MBO EC flux data. Applying this BER with PAR and temperature, the model showed good agreement with our EC flux measurement data (slope: $0.93, R^{2}: 0.89, n=388$ ), with the model slightly underestimating observations on average by $7 \%$. This basal emission rate is at least 1.2 times larger than previously reported in summer 1999 and the daytime emission also increased from summer 1998 and 1999 but not 
Table 3. Modeled values for basal mission rate $\left(\mathrm{BER}_{T}\right.$ and $\left.\mathrm{BER}_{T+L}\right)$ and temperature-dependence factor $(\beta)$.

\begin{tabular}{lll}
\hline Compound & $\begin{array}{l}\text { Basal emission rate at } 30{ }^{\circ} \mathrm{C}, \\
\text { BER }\left[\mathrm{mg} \mathrm{C} \mathrm{m}^{-2} \mathrm{~h}^{-1}\right]\end{array}$ & $\beta\left[{ }^{\circ} \mathrm{C}^{-1}\right]$ \\
\hline MBO + isoprene $(m / z$ 69) & $(3.8 \pm 0.70)^{\mathrm{a}}$ & $(\text { N.A. })^{\mathrm{b}}$ \\
Monoterpenes $(m / z$ 81) & $0.60 \pm 0.14$ & $0.12 \pm 0.01$ \\
Methanol $(m / z$ 33) & $0.54 \pm 0.17(0.71 \pm 0.21)^{\mathrm{a}}$ & $0.08 \pm 0.01$ (N.A. $)^{\mathrm{b}}$ \\
Acetone $(m / z$ 59) & $0.24 \pm 0.14$ & $0.09 \pm 0.04$ \\
Acetaldehyde $(m / z$ 45) & $0.13 \pm 0.07$ & $0.07 \pm 0.05$ \\
Sesquiterpenes $(m / z$ 205) & $0.11 \pm 0.10$ & $0.07 \pm 0.09$ \\
Methyl chavicol $(m / z$ 149) & $0.08 \pm 0.06$ & $0.20 \pm 0.06$ \\
\hline
\end{tabular}

a Basal emission rate at PAR of $1000 \mu \mathrm{mol} \mathrm{m} \mathrm{m}^{-2} \mathrm{~s}^{-1}$ and air temperature of $30^{\circ} \mathrm{C}$ for light + temperature algorithm.

b Not available for light + temperature algorithm. Detailed equations are described in Eqs. (7)-(9)

linearly (Baker et al., 1999; Schade and Goldstein, 2001; Bouvier-Brown et al., 2012). Daytime maxima of 1.2, 1.7, and $2.6 \mathrm{mg} \mathrm{C} \mathrm{m}^{-2} \mathrm{~h}^{-1}$ were observed for years 1998, 1999, and 2009, respectively. The shaded area below the canopy has increased as the forest has matured, so lower emission capacity in lower canopy is expected while an overall increase is expected due to the increase in emitting biomass at the site. Based on tree survey, the biomass of the site in summer $2009\left(1005 \mathrm{~g} \mathrm{~m}^{-2}\right)$ has increased at least 5 times more from summer $1998\left(184 \mathrm{~g} \mathrm{~m}^{-2}\right)$.

Methanol emission is also known to be correlated with light and temperature (Nemecek-Marshall et al., 1995; Schade and Goldstein, 2001). Interestingly, our vertical gradients for methanol shown in Fig. 4 strongly indicate nighttime emission and this is similar with monoterpene gradients, suggesting the main emission driver is temperature. In contrast, the daytime mixing ratio pattern is similar to that of MBO, not like monoterpenes, indicating temperature and light dependent emission is important during the day. In addition, the flux pattern is similar to that of monoterpenes in the morning when upward flux starts to increase but similar to that of MBO in the afternoon when the flux decreases. This suggests methanol emission is possibly less dependent on light, and this may be due to methanol emission from the soil. Soil methanol emission has been reported by Schade and Goldstein (2001) and Schade and Custer (2004). Based on our analysis of both emission model algorithms, the model of light + temperature for methanol $\left(\mathrm{BER}_{T+L}: 0.71 \pm 0.21 \mathrm{mg} \mathrm{C} \mathrm{m}^{-2} \mathrm{~h}^{-1}\right)$ resulted in better correlation with EC flux measurements (slope: $0.91, R^{2}$ : 0.74, $n=351$ ) for the daytime data. This is mainly due to methanol emissions being dominated by release from plants through stomata during the day. Our 2009 measurements had at least 2 times lower emission for daytime fluxes than summer 1999. This is possibly due to understory shrub removal performed in spring 1999, which may have induced an unusually large emission due to decay of plant debris during summer 1999 (Warneke et al., 1999). Methanol emission is also associated with pectin demethylation when cell walls elongate during leaf/needle expansion, as plant growth is recognized as the primary global source of methanol to the atmosphere (Fall and Benson, 1996; Galbally and Kirstine, 2002). Methanol bursts from expanding needles is a phenomenon that may have been occurring at higher rates in summer 1999 when pine trees were younger and growing more rapidly as compared to the pine trees in 2009. Moreover, a limited understory biomass in 1999 represented a minor sink for methanol, while in 2009 dense understory vegetation may have represented a sink for this OVOC (Bouvier-Brown et al., 2012).

In addition to these three dominant BVOCs, acetone, acetaldehyde, sesquiterpenes, and methyl chavicol have been reported as significant emissions from this site (Schade and Goldstein, 2001; Bouvier-Brown et al., 2009c), and our estimations of flux via $K$-theory are also consistent with these reports. Diurnal cycles of emissions for these compounds correlated better with that of monoterpenes than MBO, suggesting mainly temperature dependent emission. By assuming temperature as the main emission driver, we determined $\mathrm{BER}_{T}$ and $\beta$, as summarized in Table 3, for these 4 compounds. For acetone and acetaldehyde, we found slightly smaller $\mathrm{BER}_{T}$ and $\beta$ than those reported by Schade and Goldstein (2001), but within the uncertainty range. The daytime fluxes and concentrations showed similar magnitude to summer 1999, which is interesting since the biomass of the site has increased substantially over this $10 \mathrm{yr}$ period.

Leaf-scale emission rates of monoterpenes, sesquiterpenes and methyl chavicol were previously reported from this site (Bouvier-Brown et al., 2009c), but canopy-scale fluxes of sesquiterpenes and methyl chavicol have not been previously reported. We estimated the canopy-scale basal emission rate by multiplying the ecosystem foliar density (1005 g [dry weight] $\mathrm{m}^{-2}$ for BEARPEX 2009) to leaf-scale basal emission rate and applied the emission model using the scaled $\mathrm{BER}_{T}$ with $\beta$. Figure 11 presents temperature dependent emissions for monoterpenes and sesquiterpenes from leaf-scale emissions, canopy-scale fluxes, and temperaturealgorithm basal emission model results optimized for this study. For monoterpenes, the canopy-level emissions are in 

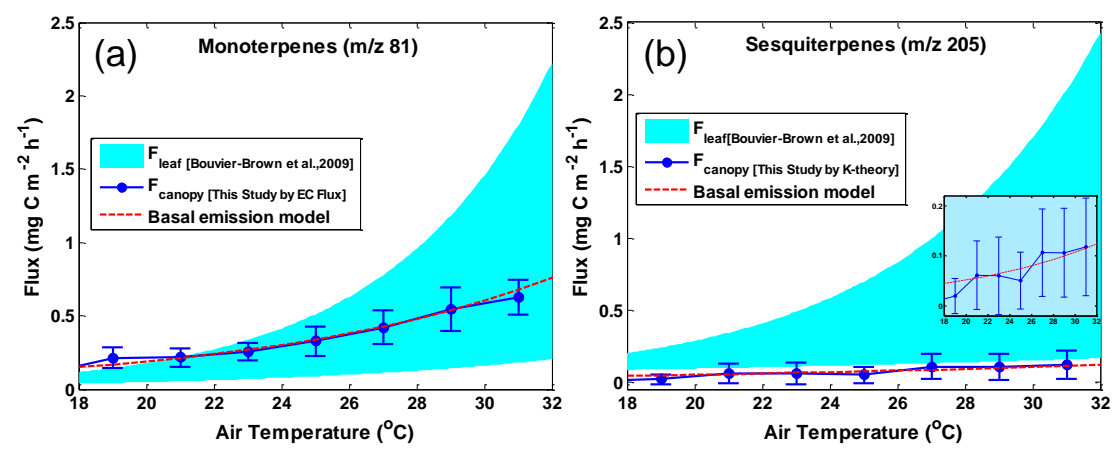

Fig. 11. Comparisons between leaf-scale emissions and canopy-scale emissions of (a) monoterpenes and (b) sesquiterpenes as a function of temperature. Shaded area indicates the range of expected canopy-level emissions from leaf-scale emissions reported previously by BouvierBrown et al. (2009). Blue dots represent canopy-scale (a) eddy covariance flux for monoterpenes and (b) flux determined by the similarity method using the universal $K$ for sesquiterpenes. All fluxes were aggregated into $2{ }^{\circ} \mathrm{C}$ temperature bins, and error bars denote standard deviations. Red dotted line represents basal emission model optimized for this study based on the canopy-scale fluxes, and the inset in (b) enlarges the vertical scale, showing the exponential relationship between temperature and sesquiterpene flux.

the middle of the range of leaf-scale emissions, and this indicates little or no loss before escaping the canopy. In contrast, sesquiterpenes are known to be oxidized rapidly in the tree canopy due to their high reactivity (Ciccioli et al., 1999; Bouvier-Brown et al., 2009c); this can justify the lower emissions measured at the canopy level as compared to upscaled emission from leaf-level measurements. Moreover, assuming the majority of sesquiterpenes are very reactive with hydroxyl radical and/or ozone, sesquiterpene flux estimated by $K$-theory may be considered an upper limit due to chemical loss between two measurement heights. For methyl chavicol, we derived a lower $\mathrm{BER}_{T}\left(0.08 \pm 0.06 \mathrm{mg} \mathrm{C} \mathrm{m}^{-2} \mathrm{~h}^{-1}\right)$ from the canopy-scale flux data than was reported for leafscale measurements (range $0.16-1.1 \mathrm{mg} \mathrm{C} \mathrm{m}^{-2} \mathrm{~h}^{-1}$, scaled for canopy scale) by Bouvier-Brown et al. (2009c), but we observed a higher $\beta\left(0.2 \pm 0.06^{\circ} \mathrm{C}^{-1}\right.$ for this study, and the range of $0.12-0.2^{\circ} \mathrm{C}^{-1}$ for leaf scale). Bouvier-Brown et al. (2009b) reported that methyl chavicol emission accounted for $4-24 \%$ of carbon mass emitted as MBO. Our methyl chavicol to $\mathrm{MBO}$ ratios were in the range $0.8-7.8 \%$ during hours 13:00-15:00 when methyl chavicol and MBO emission were maximum, consistent with the lower end of the range previously reported.

\section{Summary}

Proton transfer reaction-quadrupole mass spectrometry (PTR-QMS) has been applied to the disjunct eddy covariance method for measurement of BVOC fluxes for 4 ion species in this study. To quantify fluxes of a broader range of BVOCs, we simultaneously measured EC fluxes and vertical gradients of BVOCs during BEARPEX 2009. Using a flux-gradient relationship (" $K$-theory"), we successfully determined fluxes of 14 BVOC species in addition to $\mathrm{MBO}$, monoterpenes, and methanol by disjunct EC.
MBO $(m / z 69)$ was the dominant BVOC emission observed $\left(0.90 \mathrm{mg} \mathrm{C} \mathrm{m}^{-2} \mathrm{~h}^{-1}\right.$ in a $24 \mathrm{~h}$ mean), followed by monoterpenes $(\mathrm{m} / \mathrm{z}$ 81) and methanol $(\mathrm{m} / \mathrm{z} 33)$, which were similar ( 0.20 and $0.18 \mathrm{mg} \mathrm{C} \mathrm{m}^{-2} \mathrm{~h}^{-1}$, respectively). Fluxes of the other 14 BVOC species all showed net emission, with $24 \mathrm{~h}$ mean total emission of $0.2 \mathrm{mg} \mathrm{C} \mathrm{m}^{-2} \mathrm{~h}^{-1}$, equivalent to monoterpene or methanol emissions. Of these 14 , acetone $(\mathrm{m} / \mathrm{z}$ 59) and acetaldehyde $(\mathrm{m} / \mathrm{z} 45)$ emissions were largest at 0.07 and $0.04 \mathrm{mg} \mathrm{Cm}^{-2} \mathrm{~h}^{-1}$, respectively, followed by sesquiterpene $\left(\mathrm{m} / \mathrm{z} 205,0.03 \mathrm{mg} \mathrm{C} \mathrm{m}^{-2} \mathrm{~h}^{-1}\right)$, methyl chavi$\operatorname{col}\left(\mathrm{m} / z 149,0.02 \mathrm{mg} \mathrm{C} \mathrm{m}^{-2} \mathrm{~h}^{-1}\right)$, and a lower level of emission for all the others (less than $0.01 \mathrm{mg} \mathrm{C} \mathrm{m}^{-2} \mathrm{~h}^{-1}$ for each). By comparing with leaf-scale emission of monoterpenes and sesquiterpenes previously studied at the site, we found there was significant chemical loss of sesquiterpenes before they could escape the forest canopy, but not for monoterpenes, consistent with previous studies (Ciccioli et al., 1999; Bouvier-Brown et al., 2009a). Overall, estimating BVOC emissions using the flux-gradient relationship applied to direct measurements proved to be a useful method for investigation of ecosystem scale BVOC fluxes.

Acknowledgements. This research was supported by the National Science Foundation Atmospheric Chemistry Program Award Number 0922562. We thank Sierra Pacific Industries for the use of their land and the Blodgett Forest Research Station staff for operational support. We also thank C. Park and G. Schade at Texas A\&M University for sharing the GC-FID data.

Edited by: J. Rinne

\section{References}

Andreae, M. O. and Crutzen, P. J.: Atmospheric aerosols: Biogeochemical sources and role in atmospheric chemistry, Science, 276, 1052-1058, 1997. 
Baker, B., Guenther, A., Greenberg, J., Goldstein, A., and Fall, R.: Canopy fluxes of 2-methyl-3-buten-2-ol over a ponderosa pine forest by relaxed eddy accumulation: Field data and model comparison, J. Geophys. Res.-Atmos., 104, 26107-26114, 1999.

Baldocchi, D. D., Hicks, B. B., and Meyers, T. P.: Measuring Biosphere-Atmosphere Exchanges of Biologically Related Gases with Micrometeorological Methods, Ecology, 69, 13311340, 1988

Bouvier-Brown, N. C., Goldstein, A. H., Gilman, J. B., Kuster, W. C., and de Gouw, J. A.: In-situ ambient quantification of monoterpenes, sesquiterpenes, and related oxygenated compounds during BEARPEX 2007: implications for gas- and particle-phase chemistry, Atmos. Chem. Phys., 9, 5505-5518, doi:10.5194/acp-9-5505-2009, 2009a.

Bouvier-Brown, N. C., Goldstein, A. H., Worton, D. R., Matross, D. M., Gilman, J. B., Kuster, W. C., Welsh-Bon, D., Warneke, C., de Gouw, J. A., Cahill, T. M., and Holzinger, R.: Methyl chavicol: characterization of its biogenic emission rate, abundance, and oxidation products in the atmosphere, Atmos. Chem. Phys., 9, 2061-2074, doi:10.5194/acp-9-2061-2009, 2009b.

Bouvier-Brown, N. C., Holzinger, R., Palitzsch, K., and Goldstein, A. H.: Large emissions of sesquiterpenes and methyl chavicol quantified from branch enclosure measurements, Atmos. Environ., 43, 389-401, doi:10.1016/j.atmosenv.2008.08.039, 2009c.

Bouvier-Brown, N. C., Schade, G. W., Misson, L., Lee, A., McKay, M., and Goldstein, A. H.: Contributions of biogenic volatile organic compounds to net ecosystem carbon flux in a ponderosa pine plantation, Atmos. Environ., 60, 527-533, doi:10.1016/j.atmosenv.2012.06.070, 2012.

Chameides, W. L., Lindsay, R. W., Richardson, J., and Kiang, C. S.: The Role of Biogenic Hydrocarbons in Urban Photochemical Smog - Atlanta as a Case-Study, Science, 241, 1473-1475, 1988.

Choi, W., Faloona, I. C., McKay, M., Goldstein, A. H., and Baker, B.: Estimating the atmospheric boundary layer height over sloped, forested terrain from surface spectral analysis during BEARPEX, Atmos. Chem. Phys., 11, 6837-6853, doi:10.5194/acp-11-6837-2011, 2011.

Ciccioli, P., Brancaleoni, E., Frattoni, M., Di Palo, V., Valentini, R., Tirone, G., Seufert, G., Bertin, N., Hansen, U., Csiky, O., Lenz, R., and Sharma, M.: Emission of reactive terpene compounds from orange orchards and their removal by within-canopy processes, J. Geophys. Res.-Atmos., 104, 8077-8094, 1999.

de Gouw, J. and Warneke, C.: Measurements of volatile organic compounds in the earth's atmosphere using proton-transferreaction mass spectrometry, Mass Spectrom. Rev., 26, 223-257, doi:10.1002/Mas.20119, 2007.

Di Carlo, P., Brune, W. H., Martinez, M., Harder, H., Lesher, R., Ren, X. R., Thornberry, T., Carroll, M. A., Young, V., Shepson, P. B., Riemer, D., Apel, E., and Campbell, C.: Missing OH reactivity in a forest: Evidence for unknown reactive biogenic VOCs, Science, 304, 722-725, 2004.

Dillon, M. B., Lamanna, M. S., Schade, G. W., Goldstein, A. H., and Cohen, R. C.: Chemical evolution of the Sacramento urban plume: Transport and oxidation, J. Geophys. Res.-Atmos., 107, 4045, doi:10.1029/2001jd000969, 2002.

Dreyfus, G. B., Schade, G. W., and Goldstein, A. H.: Observational constraints on the contribution of isoprene oxidation to ozone production on the western slope of the Sierra Nevada, California,
J. Geophys. Res.-Atmos., 107, 4365, doi:10.1029/2001jd001490, 2002.

Fall, R. and Benson, A. A.: Leaf methanol - The simplest natural product from plants, Trends Plant Sci., 1, 296-301, 1996.

Fares, S., Goldstein, A., and Loreto, F.: Determinants of ozone fluxes and metrics for ozone risk assessment in plants, J. Exp. Bot., 61, 629-633, doi:10.1093/Jxb/Erp336, 2010.

Fares, S., Park, J.-H., Gentner, D. R., Weber, R., Ormeño, E., Karlik, J., and Goldstein, A. H.: Seasonal cycles of biogenic volatile organic compound fluxes and concentrations in a California citrus orchard, Atmos. Chem. Phys., 12, 9865-9880, doi:10.5194/acp12-9865-2012, 2012.

Foken, T. and Wichura, B.: Tools for quality assessment of surfacebased flux measurements, Agr. Forest Meteorol., 78, 83-105, 1996.

Fuentes, J. D., Wang, D., Neumann, H. H., Gillespie, T. J., DenHartog, G., and Dann, T. F.: Ambient biogenic hydrocarbons and isoprene emissions from a mixed deciduous forest, J. Atmos. Chem., 25, 67-95, doi:10.1007/Bf00053286, 1996.

Fuentes, J. D., Lerdau, M., Atkinson, R., Baldocchi, D., Bottenheim, J. W., Ciccioli, P., Lamb, B., Geron, C., Gu, L., Guenther, A., Sharkey, T. D., and Stockwell, W.: Biogenic hydrocarbons in the atmospheric boundary layer: A review, B. Am. Meteorol. Soc., 81, 1537-1575, 2000.

Galbally, I. E. and Kirstine, W.: The production of methanol by flowering plants and the global cycle of methanol, J. Atmos. Chem., 43, 195-229, 2002.

Goldstein, A. H. and Galbally, I. E.: Known and unexplored organic constituents in the earth's atmosphere, Environ. Sci. Technol., 41, 1514-1521, 2007.

Goldstein, A. H., Fan, S. M., Goulden, M. L., Munger, J. W., and Wofsy, S. C.: Emissions of ethene, propene, and 1-butene by a midlatitude forest, J. Geophys. Res.-Atmos., 101, 9149-9157, 1996.

Goldstein, A. H., Goulden, M. L., Munger, J. W., Wofsy, S. C., and Geron, C. D.: Seasonal course of isoprene emissions from a midlatitude deciduous forest, J. Geophys. Res.-Atmos., 103, 3104531056, 1998

Goldstein, A. H., Hultman, N. E., Fracheboud, J. M., Bauer, M. R., Panek, J. A., Xu, M., Qi, Y., Guenther, A. B., and Baugh, W.: Effects of climate variability on the carbon dioxide, water, and sensible heat fluxes above a ponderosa pine plantation in the Sierra Nevada (CA), Agr. Forest Meteorol., 101, 113-129, 2000.

Guenther, A., Hewitt, C. N., Erickson, D., Fall, R., Geron, C., Graedel, T., Harley, P., Klinger, L., Lerdau, M., Mckay, W. A., Pierce, T., Scholes, B., Steinbrecher, R., Tallamraju, R., Taylor, J., and Zimmerman, P.: A Global-Model of Natural Volatile Organic-Compound Emissions, J. Geophys. Res.-Atmos., 100, 8873-8892, 1995.

Guenther, A., Karl, T., Harley, P., Wiedinmyer, C., Palmer, P. I., and Geron, C.: Estimates of global terrestrial isoprene emissions using MEGAN (Model of Emissions of Gases and Aerosols from Nature), Atmos. Chem. Phys., 6, 3181-3210, doi:10.5194/acp-63181-2006, 2006.

Guenther, A. B., Zimmerman, P. R., Harley, P. C., Monson, R. K., and Fall, R.: Isoprene and Monoterpene Emission Rate Variability - Model Evaluations and Sensitivity Analyses, J. Geophys. Res.-Atmos., 98, 12609-12617, 1993. 
Harley, P., Fridd-Stroud, V., Greenberg, J., Guenther, A., and Vasconcellos, P.: Emission of 2-methyl-3-buten-2-ol by pines: A potentially large natural source of reactive carbon to the atmosphere, J. Geophys. Res.-Atmos., 103, 25479-25486, 1998.

Holzinger, R., Lee, A., Paw, K. T., and Goldstein, U. A. H.: Observations of oxidation products above a forest imply biogenic emissions of very reactive compounds, Atmos. Chem. Phys., 5, 67-75, doi:10.5194/acp-5-67-2005, 2005.

Holzinger, R., Lee, A., McKay, M., and Goldstein, A. H.: Seasonal variability of monoterpene emission factors for a ponderosa pine plantation in California, Atmos. Chem. Phys., 6, 1267-1274, doi:10.5194/acp-6-1267-2006, 2006.

Horst, T. W.: A simple formula for attenuation of eddy fluxes measured with first-order-response scalar sensors, Bound.-Lay. Meteorol., 82, 219-233, 1997.

Jang, M. S., Czoschke, N. M., Lee, S., and Kamens, R. M.: Heterogeneous atmospheric aerosol production by acid-catalyzed particle-phase reactions, Science, 298, 814-817, 2002.

Karl, T. G., Spirig, C., Rinne, J., Stroud, C., Prevost, P., Greenberg, J., Fall, R., and Guenther, A.: Virtual disjunct eddy covariance measurements of organic compound fluxes from a subalpine forest using proton transfer reaction mass spectrometry, Atmos. Chem. Phys., 2, 279-291, doi:10.5194/acp-2-279-2002, 2002.

Kurpius, M. R. and Goldstein, A. H.: Gas-phase chemistry dominates $\mathrm{O}-3$ loss to a forest, implying a source of aerosols and hydroxyl radicals to the atmosphere, Geophys. Res. Lett., 30, 1371, doi:10.1029/2002g1016785, 2003.

Kurpius, M. R., McKay, M., and Goldstein, A. H.: Annual ozone deposition to a Sierra Nevada ponderosa pine plantation, Atmos. Environ., 36, 4503-4515, 2002.

Lamanna, M. S. and Goldstein, A. H.: In situ measurements of C2-C-10 volatile organic compounds above a Sierra Nevada ponderosa pine plantation, J. Geophys. Res.-Atmos., 104, $21247-$ 21262, 1999.

Lee, A., Schade, G. W., Holzinger, R., and Goldstein, A. H.: A comparison of new measurements of total monoterpene flux with improved measurements of speciated monoterpene flux, Atmos. Chem. Phys., 5, 505-513, doi:10.5194/acp-5-505-2005, 2005.

Lee, X., Massman, W. J., and Law, B. E.: Handbook of micrometeorology: a guide for surface flux measurement and analysis, Atmos. Ocean. Sci. Lib., 29, Kluwer Academic, Dordrecht, Boston, London, 250 pp., 2004.

Lindinger, W., Hansel, A., and Jordan, A.: On-line monitoring of volatile organic compounds at pptv levels by means of protontransfer-reaction mass spectrometry (PTR-MS) - Medical applications, food control and environmental research, Int. J. Mass. Spectrom., 173, 191-241, 1998.

Massman, W. J.: The Attenuation of Concentration Fluctuations in Turbulent-Flow through a Tube, J. Geophys. Res.-Atmos., 96, 15269-15273, 1991.

Moore, C. J.: Frequency-Response Corrections for EddyCorrelation Systems, Bound.-Lay. Meteorol., 37, 17-35, 1986.

Nemecek-Marshall, M., Macdonald, R. C., Franzen, F. J., Wojciechowski, C. L., and Fall, R.: Methanol Emission from Leaves - Enzymatic Detection of Gas-Phase Methanol and Relation of Methanol Fluxes to Stomatal Conductance and Leaf Development, Plant Physiol., 108, 1359-1368, 1995.
Park, J.-H., Goldstein, A. H., Timkovsky, J., Fares, S., Weber, R., Karlik, J., and Holzinger, R.: Active Atmosphere-Ecosystem Exchange of the Vast Majority of Detected Volatile Organic Compounds, Science, 341, 643-647, doi:10.1126/science.1235053, 2013, 2013.

Ren, X., Gao, H., Zhou, X., Crounse, J. D., Wennberg, P. O., Browne, E. C., LaFranchi, B. W., Cohen, R. C., McKay, M., Goldstein, A. H., and Mao, J.: Measurement of atmospheric nitrous acid at Bodgett Forest during BEARPEX2007, Atmos. Chem. Phys., 10, 6283-6294, doi:10.5194/acp-10-6283-2010, 2010.

Rinne, H. J. I., Guenther, A. B., Warneke, C., de Gouw, J. A., and Luxembourg, S. L.: Disjunct eddy covariance technique for trace gas flux measurements, Geophys. Res. Lett., 28, 3139-3142, 2001.

Rummel, U., Ammann, C., Kirkman, G. A., Moura, M. A. L., Foken, T., Andreae, M. O., and Meixner, F. X.: Seasonal variation of ozone deposition to a tropical rain forest in southwest Amazonia, Atmos. Chem. Phys., 7, 5415-5435, doi:10.5194/acp-75415-2007, 2007.

Ruuskanen, T. M., Müller, M., Schnitzhofer, R., Karl, T., Graus, M., Bamberger, I., Hörtnagl, L., Brilli, F., Wohlfahrt, G., and Hansel, A.: Eddy covariance VOC emission and deposition fluxes above grassland using PTR-TOF, Atmos. Chem. Phys., 11, 611-625, doi:10.5194/acp-11-611-2011, 2011.

Schade, G. W. and Custer, T. G.: OVOC emissions from agricultural soil in northern Germany during the 2003 European heat wave, Atmos. Environ., 38, 6105-6114, doi:10.1016/j.atmosenv.2004.08.017, 2004.

Schade, G. W. and Goldstein, A. H.: Fluxes of oxygenated volatile organic compounds from a ponderosa pine plantation, J. Geophys. Res.-Atmos., 106, 3111-3123, 2001.

Schade, G. W. and Goldstein, A. H.: Increase of monoterpene emissions from a pine plantation as a result of mechanical disturbances, Geophys. Res. Lett., 30, 1380, doi:10.1029/2002g1016138, 2003.

Schade, G. W., Goldstein, A. H., Gray, D. W., and Lerdau, M. T.: Canopy and leaf level 2-methyl-3-buten-2-ol fluxes from a ponderosa pine plantation, Atmos. Environ., 34, 3535-3544, 2000.

Smeets, C. J. P. P., Holzinger, R., Vigano, I., Goldstein, A. H., and Röckmann, T.: Eddy covariance methane measurements at a Ponderosa pine plantation in California, Atmos. Chem. Phys., 9, 8365-8375, doi:10.5194/acp-9-8365-2009, 2009.

Tingey, D. T., Manning, M., Grothaus, L. C., and Burns, W. F.: Influence of Light and Temperature on Monoterpene Emission Rates from Slash Pine, Plant Physiol., 65, 797-801, 1980.

Warneke, C., Karl, T., Judmaier, H., Hansel, A., Jordan, A., Lindinger, W., and Crutzen, P. J.: Acetone, methanol, and other partially oxidized volatile organic emissions from dead plant matter by abiological processes: Significance for atmospheric $\mathrm{HO}_{\mathrm{x}}$ chemistry, Global Biogeochem. Cy., 13, 9-17, 1999.

Wilczak, J. M., Oncley, S. P., and Stage, S. A.: Sonic anemometer tilt correction algorithms, Bound.-Lay. Meteorol., 99, 127-150, 2001.

Wolfe, G. M., Thornton, J. A., Yatavelli, R. L. N., McKay, M., Goldstein, A. H., LaFranchi, B., Min, K.-E., and Cohen, R. C.: Eddy covariance fluxes of acyl peroxy nitrates (PAN, PPN and MPAN) above a Ponderosa pine forest, Atmos. Chem. Phys., 9, 615-634, doi:10.5194/acp-9-615-2009, 2009. 